\title{
Uma ponte teórica entre o passado e o futuro do livro
}

André Carlos Moraes ${ }^{1}$

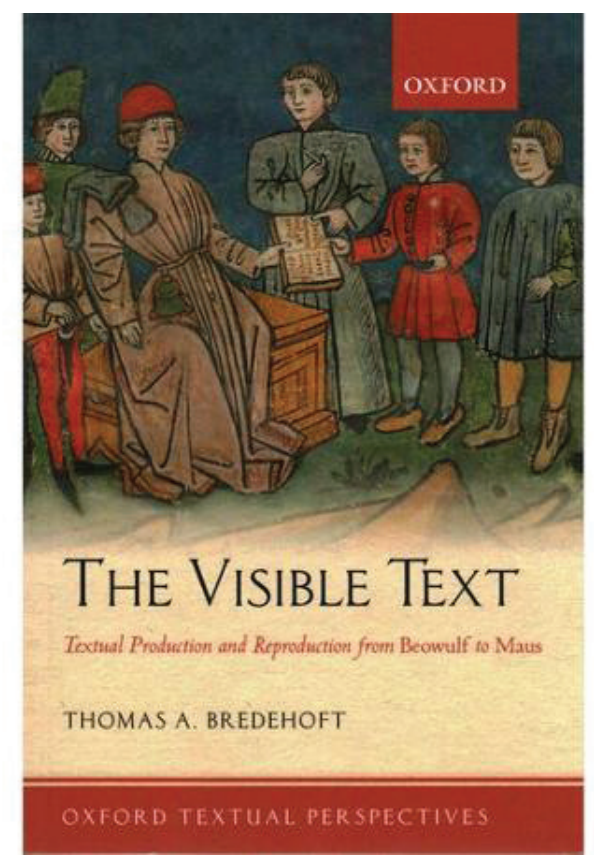

1 Mestre e doutorando pelo Programa de Pós-Graduação em Comunicação e Informação da Universidade Federal do Rio Grande do Sul (PPGCOM UFRGS). andrecmoraes@uol.com.br. 
Resumo

Resenha do livro BREDEHOFT, Thomas A. The visible text: textual production and reproduction from Beowulf to Maus. Oxford: Oxford University Press, 2014.

Palavras-chave

Livro, história do livro, história da mídia.

\section{Abstract}

Review on the book BREDEHOFT, Thomas A. The visible text: textual production and reproduction from Beowulf to Maus. Oxford: Oxford University Press, 2014.

\section{Keywords}

Book, history of the book, media history. 
Quem trabalha em pesquisas sobre a produção editorial contemporânea, especialmente na era digital, corre o risco de esbarrar no problema da delineação teórica do livro. Autores como Roger Chartier, Robert Darnton e John B. Thompson se dedicaram, na última década, ao esforço de tentar compreender como se articulam os contrastes e continuidades entre o livro impresso, da era de Gutenberg, e produtos virtuais como os e-books. Este esforço conceitual costuma passar pela readequação de modelos mais antigos, às vezes com a proposição de novas categorias e operadores de análise que possuam suficiente versatilidade para acomodar tanto os objetos empíricos antigos quanto os novos.

É neste panorama que se insere o livro The visible text, de Thomas A. Bredehoft, autor especializado, justamente, na confluência entre história da literatura e história da mídia. Ele realiza uma análise, concentrada principalmente no mundo anglo-saxônico, que procura captar mudanças de paradigma na produção e reprodução textual ao longo de várias eras, desde a época dos manuscritos até as produções atuais. Especialmente interessante para quem se dedica a estudos na área é a proposta do autor de utilizar um conjunto sintético porém versátil de ferramentas descritivas, algumas delas propostas por ele próprio, outras aproveitadas de autores como Jacques Derrida e Gerard Genette.

Bredehoft parte dos conceitos de "paratexto" (Genette) e "variance" (Derrida) para efetuar uma análise sobre o que define como mudanças de paradigma da leitura e publicação ao longo da história. Ele começa avaliando, por exemplo, peças entalhadas do período antigo anglo-saxônico que incorporavam conteúdo textual. Seu primeiro objeto é o Franks Casket, baú entalhado em marfim datado do século VIII, coberto de inscrições, que pertence ao acervo do British Museum. A estes objetos ele define como "produções", no sentido de que são criações feitas para serem únicas. Este modelo ou paradigma se estendia, em tempos medievais, à cultura dos manuscritos, que eram feitos em certa medida para ser únicos. Bredehoft aponta como componente desta particular cultura, por exemplo, o hábito de reciclar volumes para reaproveitar o velinho ou pergaminho, destruindo-se a cópia anterior. Neste paradigma, um manuscrito 
era entendido como uma produção, não uma cópia, e era precisamente sua condição única que permitia a inutilização, por exemplo, de um pergaminho anterior com o mesmo texto, que estivesse desgastado. $\mathrm{O}$ autor comenta que este hábito medieval hoje é visto com estranhamento por estudantes e mesmo especialistas, que nasceram sob outro paradigma e tendem a lamentar a perda de peças históricas ocorrida desta forma.

Uma fase posterior, segundo o autor, seria a cultura ainda pré-tipográfica que ele chama de "gótica", na qual já havia uma produção de múltiplas cópias, mas sem o conceito de um original imutável. É o que Bredehoft chama de "moving target original", que explica, por exemplo, a variação de cópias encontrada para as obras de autores como Geoffrey Chaucer. Ele detalha, em profundidade, a história editorial de The Canterbury tales, um dos clássicos da literatura inglesa, uma coletânea de histórias datada do século XIV. Os diferentes copistas de Chaucer, mesmo os que ele contratou em vida, tendiam a fazer diversas inclusões na obra, além de escolher a ordem de apresentação e outros detalhes, o que terminava por tornar cada cópia um exemplar único. Que o próprio Chaucer tenha sido testemunha destas variações seria um indicativo, segundo Bredehoft, de que a cultura de reprodução que ele chama de gótica era baseada em um conceito diferente de original, que não era fixo, mas sim uma transformação daquele conceito anterior, medieval, das produções únicas.

No modelo histórico criado por Bredehoft, o momento posterior é o tipográfico, em que se inaugura um paradigma diferenciado, o da cópia. Cada edição é uma tentativa de reproduzir um original perfeito (quase sempre abstrato, não um objeto com existência concreta). A edição usa um conjunto de paratextos (elementos da edição externos ao texto em si) para se legitimar. Adquire maior relevo a figura do escritor, através do mecanismo da "função autor" descrita por Michel Foucault. Este período concentra grande parte dos estudos textuais e de produção editorial, assim como fundamenta diferentes modelos conceituais, desde a conhecida nomenclatura "Galáxia de Gutenberg", de Marshall McLuhan, até construtos mais recentes como o da "Late age of 
print". Este conceito foi originalmente criado por Ted Striphas para descrever a produção editorial do final do século XX e início do XXI, mas que Bredehoft utiliza apenas de passagem, sem menção direta ao autor.

Ainda adiante na sucessão histórica de paradigmas de produção e reprodução, Bredehoft aponta que as histórias em quadrinhos representam uma ruptura, dentro de seu modelo, em relação à lógica estritamente tipográfica. Isso acontece porque este tipo de produção, em primeiro lugar, utiliza um diferente conceito de produção. Ele aprofunda a análise em torno das publicações Maus, de Art Spiegelman, e Jimmy Corrigan, de Chris Ware. Não existiria um original propriamente dito a ser copiado, uma vez que, argumenta, a produção é acabada apenas com a criação da cópia em si, pois os desenhos do autor só são finalizados dentro do próprio processo gráfico de reprodução. Os quadrinhos também possuem - caso específico da série Maus - a peculiaridade de misturar o paratexto com o texto, no sentido de que os autores, muitas vezes, utilizam a própria capa e outros elementos periféricos paratextuais para veiculação de conteúdo inédito ou autoral. Seria próprio das HQs, então, misturar texto e paratexto, tipografia e conteúdo.

Finalmente, Bredehoft aponta que o texto digital pode vir a representar um novo paradigma, diferente dos demais descritos em seu modelo, mas que ainda é cedo para analisar qual seja. Em suas conclusões, o autor aponta que "nossas práticas de crítica textual, baseadas como estão em um entendimento, fundamentado no impresso, de que o texto existe como uma estrutura ideal, linguística, são incompatíveis com as ideologias dos domínios anglo-saxônico, gótico e de quadrinhos"2 (BREDEHOFT, 2014, p.164), conhecimento que poderia embasar a recontextualização da crítica textual e da produção editorial em períodos como o atual, digital.

Para que não se faça injustiça em relação ao modelo do autor, é importante detalhar que ele não realiza uma divisão estanque dentro destas categorias 
descritivas históricas. Os paradigmas ou ideologias podem conviver ao longo dos diferentes períodos, embora Bredehoft aponte que exista a tendência à predominância de algum deles. Também há algum grau de interpenetração destes elementos constitutivos, e ele reconhece também, para dar conta disto, o conceito de "remediação", de Jay Bolter e Richard Grusin, segundo o qual uma nova tecnologia de mediação tende a incorporar outras mais antigas e também influenciá-las por sua existência.

Também é uma preocupação de Bredehoft, salientada durante as conclusões, evitar que a análise incorra no determinismo tecnológico, acusação que costuma rondar, por exemplo, trabalhos da linha investigativa originada a partir de Marshall McLuhan. Ele escreve que "talvez o argumento central deste livro seja a observação que mídias não são tecnologias, mas tecnologias associadas com ideologias de reprodução"3 (BREDEHOFT, 2014, p.163).

Embora curto - são 182 páginas -, The visible text tem o grande mérito de lançar mão de um ferramental versátil e atualizado de operadores descritivos, utilizando de forma complementar conceitos como a função autor de Foucault, os paratextos de Genette e a variação de Derrida, conjugados com outros mais recentes e ainda em aperfeiçoamento como a late age of print de Striphas e a remedição de Bolter e Grusin. A análise faz isto sem abandonar a erudição e o rigor da área de expertise de Bredehoft, os estudos literários anglo-saxônicos medievais. Como indicado pelo autor, a versatilidade deste conjunto operacional permite que ele coloque em perspectiva comparada produções ao longo de um grande período histórico, desde as eras pré-tipográficas até a produção de massa dos quadrinhos ou o advento do texto digital.

Há, naturalmente, pontos fracos e que podem ser passíveis de contraargumentação. Bredehoft detalha, nos agradecimentos do início do livro, a dificuldade de atuar em algumas áreas que não são sua especialidade (caso, em especial, das produções contemporâneas). Isso não chega a ser 
um demérito, mas em alguns pontos há, efetivamente, pequenos deslizes técnicos. Analisando as mídias contemporâneas, por exemplo, ele comenta que a "revolução digital, com sua habilidade de traduzir tudo em uma sequência de bits digitais, captura e estende a ideologicamente incansável linearidade do impresso" (BREDEHOFT, 2014, p.124). Aqui, ele parece incorrer em um equívoco comum em análises do ambiente digital, ao confundir a estrutura linear dos bits, constituída por linhas de comando dentro da máquina, com a estrutura de mediação digital, que, contrariamente, não seria linear, como costumava ser apontado por Marshall McLuhan em relação aos meios eletrônicos e, mais recentemente, é dito por Jay David Bolter e Richard Grusin em relação às mídias digitais.

Ao longo do texto, Bredehoft pode também, em alguns momentos, fazer fronteira - embora sem, necessariamente, ceder - à tentação de tensionar um pouco demais a análise, forçando a adequação de certos detalhes ao argumento principal. Isso pode ser observado quando detalha as ideologias medieval e gótica, em que a relativa escassez documental acaba tendo que ser complementada por conclusões obtidas previamente pelo autor em trabalhos anteriores. Mas isso não invalida a estrutura principal.

The visible text, além de consistir em um interessante exercício de análise literária e de erudição, pode interessar a leitores mesmo que não estejam diretamente interessados na área de estudos de história, crítica textual ou produção editorial. Ao lançar mão de descritores e mesmo exemplos que extrapolam a categoria tradicional dos textos, Bredehoft torna seu trabalho potencialmente útil, ainda, para pesquisadores de estudos culturais e, mesmo, aqueles que estejam interessados em mapear historicamente as implementações da ideologia cultural ou social. É o caso, por exemplo, da análise do autor a respeito dos medalhões devocionais que costumavam ser vendidos aos peregrinos nos centros religiosos medievais. Eles seriam uma das implementações da cultura que ele identifica como gótica, produções paralelas às formas literárias (religiosas) e, como tais, ideológicas. 
É uma obra útil para pesquisadores interessados em história da mídia, evolução do livro e até quadrinhos ou, inclusive, formas diversas de expressão na confluência entre a plasticidade e o literário, como a escultura religiosa e o artesanato devocional. Embora diga respeito basicamente ao universo anglosaxônico, não é difícil antever a utilidade dos conceitos trazidos por Bredehoft até em nosso contexto nacional, em uma história que mescla, mesmo no presente, produções que vão do cordel à experimentação gráfica ou digital. É uma fonte essencial para nos ajudar a enxergar o livro em suas várias configurações ontem e hoje, e para entender como a ideologia subjacente pode ser ela mesma, ao longo das eras, o mais visível dos textos. 


\section{Referências}

BOLTER, J. D.; GRUSIN, R. Remediation: understanding new media. Cambridge: The MIT Press, 2000.

BREDEHOFT, T. A. The visible text: textual production and reproduction from Beowulf to Maus. Oxford: Oxford University Press, 2014.

FOUCAULT, M. "Qu'est-ce qu'un auteur?" (conferência). In: Dits et écrits, I (1954-1969). Paris, Gallimard, 1994, p. 789-821.

STRIPHAS, T. The late age of print: everyday book culture from consumerism to control. New York: Columbia University Press, 2011. 